\title{
Implementing Inclusive Education In Early Childhood Settings: The Interplay and Impact of Exclusion, Teacher Qualities, and Professional Development in Ghana
}

Francis R. Ackah-Jnr, PhD

Griffith University \& Griffith College, Brisbane, Queensland, Australia

iD https://orcid.org/oooo-0002-2261-4092

Hyacinth Udah, $\mathrm{PhD}$

James Cook University, North Queensland, Australia

iD https://orcid.org/0000-0002-2681-5596

Contact:fr.ackahjnr@yahoo.com

\section{Abstract}

Inclusive education (IE) in the early years enhances young children's learning, socialization, and development; yet, children with disability are one group that is often isolated, excluded, or marginalized in early childhood education. This paper examines jointly the perceived exclusion practices, teacher qualities, and professional development and the interplay and impact of these factors on effective inclusive early childhood education. Drawing on data collected from individual interviews with teachers and headteachers in a large early childhood and school setting in Ghana, findings of this qualitative study indicate the exclusion practices of teachers. The findings suggest that resistance to IE limits learning, engagement, and social opportunities for children, especially those with disability. The findings also identify that effective teacher qualities and professional development enhance the provision of quality inclusive early childhood education. The study reinforces the need for improved support for teachers and to make sure that they are placed at the center of IE policy and practice.

Keywords: Early childhood; inclusive education; inclusive early childhood education; exclusion; teacher qualities; professional development

Date Submitted: August 16, 2020 | Date Published: May 5, 2021

\section{Recommended Citation}

Ackah-Jnr, F. R., \& Udah, H. (2021). Implementing inclusive education in early childhood settings: The interplay and impact of exclusion, teacher qualities, and professional development in Ghana. Journal of Educational Research and Practice, 11, 112-125. https://doi.org/10.5590/JERAP.2021.11.1.08

\section{Introduction}

Early childhood is a stage where all young children can have purposeful experiential learning and social opportunities. As an international term, early childhood denotes the period from birth to age 8 (Bredekamp, 2020; Deiner, 2013; Essa, 2014) during which children receive a variety of care and educational services

Note: We thank the Ghana Education Service and the teachers and headteachers of the ECE center and school who devoted precious time and contributed insights for this study. The first author would like to thank Griffith University for awarding scholarship for the pursuit of a larger doctoral study from which this study is derived. 
(Bartolo et al., 2016; Bredekamp, 2020; Deiner, 2013; Essa, 2014). Early childhood education (ECE) is usually a provision, service, or practice aimed at addressing social equity and equality and minimizes early disadvantages (OECD, 2015), and this further helps to empower all children and develop their potential (Ackah-Jnr, 2018). Early childhood is a window of opportunity for preventing potential delays and difficulties (Bartolo et al., 2016), but, due to socio-contextual differences, especially in the global South ${ }^{1}$, not all children participate or are included in quality ECE programs. For this reason, ECE is sometimes marked by exclusion for many children, particularly those with disability or disadvantage.

To create equitable programs and services for all children, inclusive early childhood education (IECE) has increasingly become a major focus of national governments, education systems, and schools (Ainscow, 2020). IECE has the potential to alter the way society perceives the early education of children. It is driven by arguments that inclusion and ECE are inseparable. Research shows that quality ECE is important for all children, so commencing inclusion in early childhood is a prudent thing to do, and it is morally or ethically sound (Smith et al., 2012). Essentially, early childhood inclusion is integral to quality early childhood programs and classrooms (Guralnick \& Bruder, 2016) and a means to ensuring all children have quality early growth and development. IECE is defined as the right to equal education and social experiences for all children with and without disability from birth to 8 years (Cologon, 2014; Smith et al., 2012). It is considered a best practice, process, and approach (Guralnick \& Bruder, 2016) and it is committed to preserving children's right to learning, playing, developing, and living or socializing together in early childhood settings. For Guralnick and Bruder (2016), four key imperatives provide a strong framework to operationalize IECE practice: access, accommodations and feasibility, developmental progress, and social integration. Notions of IE from the global North (as opposed to the global South) neglect cultural contexts, as in Ghana, but we believe the ultimate goal of inclusion is that all children will at least do well developmentally, educationally, and socially in inclusive early settings and programs when they are appropriately supported.

In Ghana, IE is a principal goal of the Inclusive Education Policy (Ministry of Education [MoE], 2015), Education Strategic Plans (ESP 2010-2020 \& ESP 2018-2030) and Early Childhood Education Policy (2004). Recently, the new National Teachers' Standards (MoE, 2017) recommended the use of inclusive approaches in early childhood settings. According to the 2010 Population and Housing Census, the prevalence of children with disability aged between 4 and 17 years old is $1.6 \%$ (130,00o children) of the estimated 24.6 million people. While this figure may be underestimated due to low detection rates and social stigma, enrollment of children with disability ranges from just $0.2 \%$ to $0.4 \%$ of total enrollment in Kindergarten (KG). Children with disability have lower attendance rates compared to those without disability at all levels of pretertiary education and the lowest attendance (MoE, 2012). Many children with disability, according to Kuyini and Abosi (2014), are excluded from regular school activities in Ghana.

Ghana has increasing investment and expansion of ECE programs and services and the propensity to support children's development and learning (Wolf, 2020). IE is important for all children, although those with disability are one group that is mostly isolated or excluded from early childhood and school settings. This paper explores the interplay of exclusionary practices, teacher qualities, and professional development and how this impacts inclusion in ECE. The study focus is further embedded in notions that knowledgeable and skilled teachers are critical to realizing the Sustainable Development Goal 4 (SDG 4) to ensure inclusive and equitable quality education and promote lifelong learning opportunities for all (UN, 2016). Also, researchers argue that teachers with effective qualities can enhance IE in ECE settings (Allen \& Cowdery, 2015; McLeskey et al., 2017). Research indicates that teachers who are armored with knowledge, skilled pedagogically, and have favorable traits limit exclusion or foster the participation, learning, and engagement of children in early

1 The term global South is one of a family of terms, including "Third World" and "Periphery," that denote regions or people outside Europe and North America, mostly (though not all) low-income and often politically or culturally marginalized countries, experiencing large inequalities in living standards, life expectancy, and access to resources (Udah, 2021). 
childhood settings and programs (Ainscow, 2020; Hyde, 2014). To the best of our knowledge, no research exists that jointly examines exclusion practices, teacher qualities, and professional development. Three specific research questions frame the study:

1. What teacher practices promote exclusion in early childhood settings?

2. What teacher qualities support inclusive practice?

3. What professional development and learning are important for inclusive education?

\section{Ghanaian Inclusive Education Policy Context}

Ghana, a centrally situated republic and the gateway to West Africa, is part of the wider international and educational community practicing inclusive education. It has a population of 25.6 million, out of which 5 million people, an estimated 3\% of the population, are identified as having a disability of one form or the other (Ghana Statistical Service [GSS], 2010). Ghana was the first sub-Saharan African country to endorse the education of children with disability in its Education Act in 1961. In Ghanaian practice, the IE policy, strategically and aspirationally, aims to improve and adapt education and related systems and structures to ensure the educational and social inclusion of all learners, particularly those with disability and special educational needs (MoE, 2015). Ghana has, from the pre-independent era until now, shown continually increased aspirations, commitment, and leadership for IE. This has culminated in the development of local strategic policies (especially 2-year free and compulsory kindergarten as part of Basic Education for all children in public schools) and ratification of international conventions such as the United Nations Convention on the Rights of Persons with Disabilities (CRPD, 2006) and the adoption of the Sustainable Development Goals (UN, 2016).

Ghana is the first country to have ratified the UN Convention on the Rights of the Child (UNCRC) in 1990 (UNICEF Ghana, n.d). It recognizes the import of Article 24(1) of the CRPD that directs IE at the early childhood level:

States Parties recognize the right of children with disabilities to an inclusive education system at the early childhood education level, devoid of discrimination, and provided on equal opportunity as a vehicle to realising this right. An inclusive [early childhood education] system is effective to develop the full human potential and personality, sense of dignity and promote social participation.

The 1992 Constitution of Ghana legitimizes children's right to optimum growth and development, which entails the right to education during early childhood (Government of Ghana [GOG] 1992). Article 28 of the UNCRC highlights the need for States Parties, including Ghana, to develop comprehensive frameworks for early childhood care and education services that ensure the child's best interests. States Parties should ensure that the services responsible for early childhood comply with quality standards, and that "staff members possess the appropriate psychosocial qualities and are suitable, sufficiently numerous and well trained" (UN Committee on the Rights of the Child [CRC], 2006, p. 45). Article 28(1a) of the UNCRC (1989) indicates:

States Parties recognise the right of the child to education, and with a view to achieving this right progressively and on the basis of equal opportunity, they shall, in particular, make early childhood education compulsory and available free to all.

Similarly, articles 25(a) and 38(2) of the 1992 Constitution of Ghana and ECE policy (2004) recognize ECE as a basic right of the child. Accordingly, Ghana is making efforts to provide equal access, opportunities, and facilities at all educational levels, including ECE (Article 38[1]; 25[1]). The new National Teachers' Standards (MoE, 2017) mandate teachers to use inclusive pedagogies in ECE. There is thus a strong commitment to IECE at the policy level. In Ghana, IE is seen as a significant focus of current and future education provision, 
and the goal for inclusive (early childhood) education, like elsewhere, includes both the development of all children such as those with disability, within a framework of their right to quality education with opportunities equal to all. The perceived goal of IE also involves a range of academic, social, and emotional outcomes and the development of a stronger citizenship and economic workforce. This notwithstanding, multiplicity of traditional, cultural, and social beliefs or norms affect the education of children with disability in Ghana, which invariably influence the attitudes of teachers, educators, or parents towards inclusive practice. We are also aware that the conceptualization of disability and IE by some education stakeholders, including teachers and education officials, are oriented towards a deficit or medical model, which highlights the weakness, have-not, or disability of children as opposed to their ability to function with appropriate scaffolding from teachers and other educators. Generally, however, Ghanaian teachers have positive attitudes towards IE (Opoku et al., 2019).

\section{Teachers and Inclusive Early Childhood Education Practice}

Implementation of IE is conterminous with having quality and motivated teachers in early childhood and school settings that are also resourced and lubricated continually. Teachers generally play important roles in educating children and most especially in supporting the implementation of education policies and programs. Research indicates that teachers are instrumental in leading change and practice of IE and ECE (Ackah-Jnr, 2020). It is noted that teachers in Ghana, like elsewhere, are the key implementation agents and stakeholders that enact the necessary leadership and pedagogical practices that ensure young children, regardless of disability, SEN, and disadvantage, are provided appropriate care and education services to develop their potential (Ackah-Jnr, 2018; Bredekamp, 2020).

Previous research shows that teachers play strategic roles to enact age and culturally appropriate pedagogies and practices to reduce inequities and inequalities in ECE (Fluckiger et al., 2017). To do this, teachers structure practices to promote meaningful participation or interaction among all children in inclusive environments. Young children benefit from early childhood settings when teachers implement effective pedagogical practices, including differentiation, tasks analysis, and prompts to support quality inclusive programs (Allen \& Cowdery, 2015; Fluckiger et al., 2017; McLeskey et al., 2017; Tomlinson, 2014). For IECE to be effective, teacher practices must correspond to the diversity of students and ensure all students have access; teachers should plan, teach, and assess their lessons; and teachers must be interested in and support the participation and learning of all students. Effective ECE also requires that parents and the community are used as a source of support in classrooms. Active parent and community involvement is important (Wolf, 2020). Teachers who have a wealth of knowledge, skills, dispositions, and other experiences are more willing to promote good IE practices (Allen \& Cowdery, 2015; Forlin \& Sin, 2017). However, some research reports that teachers may limit participation opportunities for children with disability in early childhood settings due to inadequate knowledge or preparation (Ackah-Jnr, 2020; Forlin \& Sin, 2017).

\section{Method}

This study, a qualitative, constructivist-inspired, and naturalistic inquiry, was conducted in Cape Coast Metropolitan Assembly, the capital of the Central Region of Ghana. Cape Coast abounds in education and social intervention policies and programs targeted at increasing accessibility, inclusivity, and participation for all children. The approach fosters sense-making and interpretation of a phenomenon and articulates a worldview that reality is socially constructed (Creswell \& Creswell, 2018; Miles et al., 2014; Patton, 2015). It also claims there are multiple realities and meanings. This constructivist approach values everyday practices and is deemed useful for explaining perspectives of IE contexts.

One large ECE center and school, identified as important to yielding information on the issues under investigation and based on Patton's (2015) articulation that if it [inclusive education] happens here, it will 
happen anywhere, was selected as a critical case for the study. The study is part of doctoral research and is based on critical interviews involving open-ended structured questions with headteachers and teachers on issues of exclusion, teacher qualities, and professional development. Interviews were conducted individually and separately with participants at the school, and each interview lasted for between 30 to 45 minutes. Data used for this paper are based on digitally recorded and transcribed interviews and a few field notes. Permission to conduct this research was obtained from the Ghana Education Service and the school management, following research and ethics approval from the first author's institution.

\section{Research Site and Participant Selection}

The research site was one large mixed-sex early childhood learning center and school, located in a "high" socio-economic setting in a Sub-Metro Education Circuit of the Cape Coast Metropolitan Assembly. The school had six streams of KG and primary classes and is a preferred choice for parents to send their children to. It was selected based on several criteria: The school is noted to provide quality ECE in a welcoming environment and acts as a model center for inclusive practicum experiences for pre-service teachers. In each class about $10 \%$ of the children had disabilities, such as learning and intellectual disability, autism, and behavioral disorders and were educated along with their typically developing peers. The school collaborates with a partner higher education institution for professional development activities to support IE. Like other schools in Ghana, the school is committed to educating all children in line with Ghana Education Service's goal-providing quality education for all children (MoE, 2012).

The ECE center and school had a staff strength of over 50 lead teachers, with support teachers for some classes and one headteacher each for the KG and primary sections. For this research, only 10 participants, comprising two headteachers and eight teachers, from the ECE center and school were selected following their consent and agreement. They were selected through a purposeful sampling strategy (Creswell, 2013; Miles et al., 2014; Patton, 2015). Since the KG and primary sections of the school were headed by two different headteachers, they were automatically selected. Teachers were chosen from KG 1 and 2 and Primary 1 to 3 classes. Four female teachers were selected from KG 1 and 2 since they taught at that level and four males were selected from $\mathrm{P} 1$ to 3 . The selection criteria included those with diploma or above qualifications, significant teaching of 10 years and above, and headship experience. Two of the eight teachers had master's degrees and the other six had bachelor's or diploma. All two headteachers had master's degrees in guidance and counselling or educational administration and management. The male headteacher had over 19 years of headship experience, while the female had 18 years. In terms of teaching experience, three teachers had over 20 years of experience and a few "new" ones had close to 10 years. The demographics of participants are provided in Table 1. 
Ackah-Jnr \& Udah, 2021

Table 1: Demographic Summary of Case Participants

\begin{tabular}{lcccccc}
\hline Participant & Position & Gender & $\begin{array}{c}\text { Teaching } \\
\text { experience }\end{array}$ & $\begin{array}{c}\text { Age } \\
\text { range }\end{array}$ & Class & Qualification \\
\hline FT-Ama & Teacher & F & 24 & $41-45$ & KG1 & BEd (ECE Education) \\
FT-Aba & Teacher & F & 10 & $31-35$ & KG2 & BEd (ECE Education) \\
MT-Kwame & Teacher & M & 12 & $36-40$ & P1 & BSc (Agricultural Science) \\
MT-Kojo & Teacher & M & 15 & $36-40$ & P3 & MEd (Guidance \& Counselling) \\
MT-Kwaw & Teacher & M & 10 & $36-40$ & P2 & Diploma (Basic Education) \\
MT-Kofi & Teacher & M & 12 & $36-40$ & P1 & BEd (Primary Education) \\
FT-Akua & Teacher & F & 25 & $51-55$ & KG1 & BEd (Basic Education) \\
FT-Akos & Teacher & F & 23 & $46-50$ & KG2 & MPhil (Basic Education) \\
FHT-Ade & Head & F & 8 & $56-60$ & - & MEd (Guidance \& Counselling) \\
MHT-Aka & Head & M & 16 & $56-60$ & - & MPhil (Education Adm \& Mgt) \\
\hline
\end{tabular}

\section{Analysis}

Data from this study were analyzed thematically. Themes were generated through critical reflection and careful reading of segments of participants' interview transcripts. Although repetitive, the process enhanced our interpretive familiarity and sense-making of the data corpus (Miles et al., 2014). Following verbatim transcription of interviews, insights capturing issues on exclusion, teacher qualities, or professional development were coded and focused on more deeply to identify thematic meanings. The coding process involved sorting and categorizing data to capture meanings and emergent themes (Creswell, 2013; Miles et al., 2014), which enhanced the representation of our analytic thinking and interpretations of data. Initial coding, selection of participant illustrative extracts, and identification of themes were undertaken by the first author. The final codes and themes were agreed on after thorough review, discussion, and consensus. To foster the trustworthiness of the data analysis, we shared or discussed some transcripts or themes with some participants or employed member checking to enhance the accuracy and interpretations of our findings (Creswell, 2013). Results also involve participant and researcher voice but they are filtered through or moderated with literature. Extracts are carefully selected to capture participants' views.

\section{Results}

Analysis of responses to the open-ended interviews that were crafted from the specific research questions guiding the study revealed critical insights into inclusive practice. The findings from the interview data are important for inclusive ECE: exclusionary practices, teacher qualities, and professional development and agency.

\section{Teacher Qualities}

Participants identified that effective teacher qualities are important and they enhance IE in early childhood settings. The key among the teacher qualities is passion. 


\section{Teacher qualities, especially passion, drive inclusive education practice}

All the headteachers and most teachers indicated that passion is the most effective teacher quality essential to enhancing IE. For them, passion manifests as strong desire, love, and ambition and is what drives teachers' inclusive practice in ECE. These personal traits, including passion, love, or caring, were seen to support teachers' agency (learning) and what scaffold their everyday inclusive practices. The possession of effective qualities enabled teachers to create more meaningful opportunities to support children's learning and socializing. We identified that passionate teachers showed care, commitment, and dedication to IE. For teacher Akua, such effective qualities ensure teachers "stay and guide children with disability" and "open the doors" of inclusion. Teachers with positive qualities, mainly passion, were perceived to be willing to work with all children, parents, and other stakeholders. In her words, teacher Ama said:

$[\mathrm{M}] \mathrm{y}$ passion makes me to teach all children no matter their ability at that young age and motivated me to do Early Childhood at the university. I want to help all children, work well with parents as I did at my former school, and this keeps me going every day. If all teachers have qualities such as being passionate, caring and loving, we can include all children. Learning is key.

Teacher Ama's comment shows that IECE is all about passion. Passion is essentially a key teacher quality that can also shape teachers' career choice or path. Another teacher, Kwame, said passion makes teachers have "the heart and desire" to teach children with disability. With passion, teachers can ensure children feel accepted and safe in early childhood settings:

Some teachers have the desire and heart, so they ensure children with problems take part in lessons, are safe or feel good and learn as others. (Teacher Kwame)

Headteacher Ade added that passion enables teachers to work with all children and their parents in order to meet children's needs. She adduced,

some teachers are interested in things they do for all children with challenges, disability or not; they show other caring attitudes and behaviours to support their work with children and parents. (Headteacher Ade)

On the part of teacher Akos, passion and commitment are important traits teachers should possess. She added that teaching classes where some children have disability and other needs requires teachers who are passionate and hopeful that things will at least work for everybody:

Teachers who are committed have passion and these attributes are important to include children with disability.... The task of having to teach a class where some have disabilities need teachers that hope things will work. (Teacher Akos)

The extracts suggest that passionate teachers are also motivated to work with all children in early childhood and school settings. This draws our attention to the criticality of effective teacher qualities and how this can be honed to promote inclusive practice.

\section{Exclusion Practices}

Participants identified two main integrative practices and actions of teachers that promote exclusion in early childhood settings, hence impact effective inclusive education:

\section{a. Exclusion results from teachers' decisions and actions}

Most teachers recounted that teachers' decisions and actions led to the exclusion of children with disability or disadvantage from schools. In all, eight participants noted that teachers perpetuated exclusion through their 
in-school actions such as isolating some children with disability from class activities or decisions of not "wholly" accepting and involving all children in-school programs. Teachers perceived some children with disability to be "difficult to teach, manage or learn in classrooms," so such teachers were unprepared to individualize or differentiate activities. Teacher actions were exacerbated with the projection of self-fulfilled prophecies and negative assumptions about the capability of children with disability. As teacher Kojo stated, some teachers "pay little attention to children with disability" as they are believed to "have many learning problems or can't learn." Other children were excluded based on teachers' patronizing perceptions that teaching "children with disability [was a] waste of time." Teacher Aba noted this practice also resulted in some children being made "spectators or passive actors in most academic and social activities" of the early childhood setting.

Teacher Kofi added that some "teachers use inappropriate pedagogies that do not promote effective teaching and learning, e.g., rote learning, memorization or tasks non-differentiation" in their classrooms. This was perceived to make some children with disability to be pedagogically excluded or alienated from most learning experiences. The exclusionary actions and practices escalated if a "teacher did not support the admission of a child with disability" or "teachers felt special schools were better destinations" for the child (Teacher Kojo). Therefore, some teachers "stay-and-steer clear" of such children and this action encourages exclusion. Teacher Akos expressed these sentiments in this way:

At my first school, almost all the teachers didn't want to teach children with disability, but I had two in my KG class, so when others were brought, the head usually asked for my views. Teachers referred such children to special schools; even now some teachers in other schools do the same to children we can handle in the mainstream.... Some teachers accept them, but others aren't bothered... so they decide to isolate them most of the time if they are there.

Similarly, Headteacher Aka stated some teachers' decision to exclude children is informed by teachers' support for IE, which is reflected in their attitudes:

When teachers don't support inclusion, it's difficult. It shows in their attitudes and relations with children. They give little time to children with disability or separate them. It's hard to do this here. Other heads prevent such children from schools.

Due to the posturing of some teachers or headteachers or their decision to isolate children with disability, many participants felt there is a need to enforce practical laws that can precipitate changes in school practice to eliminate intentional exclusion. Teacher Akua maintained:

Many teachers are responsible for separating or neglecting children with disability in early childhood settings and schools unless this changes with good laws and policies that work.... The practice [exclusion] will continue.

Surprisingly, a few participants noted some teachers excluded children with disability from schools unilaterally or clandestinely without recourse to in-school consultation. This practice raises questions of power abuse. These actions of teachers were not in favor of inclusion, which fuels the thinking that some children with disability are included at their own peril to perish rather than to prevail and flourish. Teachers did not support inclusion:

Some teachers feel they are the ones in the class so if they think they can't teach or include the child with disability and the child is still admitted, they won't have anything to do with that child. The child can be there, alright, but you know.... Some headteachers do this also [long laugh...]. (Teacher Kofi) 
From teacher Kofi's extract and other interview data, it was clear that some headteachers also did not support inclusion by their refusal or decision not to admit children with disability.

\section{b. Exclusion results from resistance; teachers reject or react negatively to inclusion}

All the headteachers and teachers reported that exclusion also arose predominantly from teacher resistance to IE policy and practice. Linked to teachers' decisions and actions, such resistance was generally perpetuated through in-school exclusionary tendencies, which fuel a spiral of multiple resistance. This ranged from subtle to total resistance, e.g., unwillingness, non-acceptance, rejection, apprehension, denial, and unbelief, as well as reactive and induced attitudes towards children with disability or IE. Teacher Aba lamented that a child with disability could be admitted to a school, but "if the class teacher is not in support that child could be taken away [alienated] from class activities." Some participants noted teachers' resistance led to the selective claims they made, e.g., projecting "negative perceptions or passing judgements that inclusion makes teachers to work extra" (Teacher Kwame). Other teachers stayed defensive or made false illusions to pedagogical competence inadequacy. For many participants, teachers' non-receptiveness, rejection, or resistance to IE was mainly attitudinal and perceptual rather than claims attributed solely to lack of training. For teacher Ama, such claims were a means for some teachers to evade responsibility, or are used as a "smoke screen" for making excuses:

Some teachers close their eyes or minds.... They resist children with disability in ECE schools. It's not lack training... is not true... even they see those children with little [mild] disability to give more problems; not even the blind or severe ones.... It's not inadequate training as trained teachers complain; others are trying. These teachers want nothing to do with inclusion. It's personality, perception, or motivation issues.

Teacher Ama's quotation shows that the personality, perception, or demotivation of teachers contributed to their resistance to IE. It suggests that some teachers excluded children due to their idealization of inclusive teaching. Therefore, they can do great or small things to resist the inclusion of a child with disability in early childhood settings.

\section{Professional Development (PD) and Learning}

Effective PD, augmented with teachers' learning and research or agency, was identified as important, which can limit exclusion practices in early childhood settings.

\section{a. Professional development is essential.... Teachers should be at the center of practice}

All the headteachers and many teachers said teachers need to be at the epicenter of inclusive practice and be provided adequate PD and training. This, they believed, would limit exclusion practices. Many participants acknowledged the essence and benefits of professionally developing, equipping, or preparing teachers adequately to have inclusive knowledge, skills, and understanding. They added that inclusive practice can be fostered if teachers are knowledgeable of the broader issues of inclusion and are skilled at including diverse children using appropriate pedagogical practices such as individualized instruction, prompts, or scaffolding. For headteacher Aka, "teachers with good instructional skills, can provide one-on-one support to help children with disability learn with others or catch up lessons" in class. Teachers were perceived as the chief architects to unlock the door to IE, so they must be at the center of practice and receive appropriate PD. The extract from teacher Kwame captures this view: 
Teachers must be at the center of early childhood inclusion. Teachers don't have all the knowledge, so they need training on new inclusive issues at schools or workshops. Some teachers have the desire and heart, so it's time all teachers have the skills or training to make inclusion real for all children.

In a similar vein, headteacher Ade identified that needs-based PD can ensure teachers "stay on the top and see things" better for IE to work:

Teachers must be on the top to see things well or have knowledge and skills. Sometimes training should be done at the school, one that identifies specific problems of teachers or needs... plan... we have some children that behave in some way, so this requires special training.

\section{b. Teacher agency helps-Teachers need spaces to learn or research}

It was noted that additional spaces, resources, and opportunities for teachers to undertake research and further learning about inclusive issues can complement the PD they receive from the education system for inclusive practice. Teachers needed to self-learn to support and advance inclusive practice and programs. Teacher agency was deemed important to unravel new knowledge and skills or make discoveries about inclusive teaching. Teacher Kwame's comment portrays the criticality of teacher agency for inclusive practice:

Teachers need to have more spaces to do their own research about how things work if you have different children or learn. In learning we can encounter new things about how to include... learning from others or self helps.

For headteacher Ade, agency enables teachers to develop knowledge and skills. It also ensures teachers work or collaborate with experts for inclusive practice:

Some teachers research or learn from other people to support their [inclusive] work but if they have time to do so, it will really enrich their skills.

\section{Discussion and Conclusion}

Study findings add to the body of literature on IE from a unique context. The study shows that despite being recognized as best policy and practice, IECE has challenges. Effective IECE creates opportunity for all children to have early equitable and quality education, oriented to our collective quest to combat discrimination and marginalization, and to build an inclusive society and achieve education for all (MoE, 2015; UN, 2016). Enabling an early inclusive start to education for children with disability can ensure they also transition to other levels of education and have further opportunity for participation and belonging in inclusive settings (Bartolo et al., 2016; Cologon, 2014). Because IECE aims to facilitate the developmental trajectory of all young children, including those experiencing delays in development (Guralnick \& Bruder, 2016), teachers need actionable practices, knowledge, and skills to limit the frontiers of exclusion. Three insights from the study are discussed further.

Our findings first suggest IE is characterized by exclusionary practices that deny many young children full participation in education and social provisions in schools. As noted, exclusion recurs as an appendage of IE. It results from teachers' decisions and resistance, which is often underpinned by beliefs and attitudes such as a child's disability is due to misdeeds or the child is difficult to teach. Participants' accounts showed that teachers' actions and resistance fuel cycles of exclusion. In-school exclusion of teachers is against Ghana's Inclusive Education policy (MoE, 2015) that identifies IE as a value-based system that promotes participation, engagement, and interaction and enforces all children's entitlement to an inclusive and equitable quality education to develop their potential. In this study, teachers' exclusion practices thus raise doubts about their acceptance of IE and possibly cement the view that some children are "included for the sake of inclusion." In a 
similar Tanzanian study Miles et al. (2018) noted that teachers responded to learners with disability as their training allowed, so their practice, like that of their Ghanaian counterparts, involved inclusions and exclusions. It implies inclusion and exclusion can co-exist in schools, but inclusive practice should lead to increased presence, heightened participation, learning, and engagement of learners (Ainscow, 2020; Hyde, 2014) and to their acceptance as valued members of mainstream settings. Strikingly if some teachers or headteachers wield the power to slam the door of inclusion to some children or determine who is included, this practice questions the legitimacy of IE. Teacher resistance promotes exclusion, contrary to Ghanaian studies that found teachers to be generally positive towards IE (Kuyini \& Abosi, 2014). Research from the United States showed similarly that teachers and other staff in local early childhood programs expressed reluctance or resistance to include children with disability, resulting in inclusive programs being dictated by some children's perceived needs (Guralnick \& Bruder, 2016). This means teacher resistance to inclusion can be cross-cultural.

Interestingly, our findings highlight that positive teacher qualities are essential and promote IECE. While many teachers in early childhood and school settings enact appropriate pedagogies (Fluckiger et al., 2017) to foster the education and socialization of children with disability, teachers demonstrating effective qualities can also express positive attitudes critical to inclusive practice. Our results, like other studies, indicate that effective traits, qualities, and dispositions are not only important (Allen \& Cowdery, 2015; Cologon, 2014; McLeskey et al., 2017), but are similar to teachers with sound pedagogical knowledge, skills, and competencies for IE (McLeskey et al., 2017).

Effective qualities foster commitment, acceptance, and motivation for inclusive enhanced practice (Graham \& Scott, 2016). Motivation also promotes positive attitude development as teachers with high motivation are more willing to teach and include all children, regardless of disability (Ackah-Jnr, 2018). It can be argued that if teachers are motivated intrinsically and extrinsically, they show higher efficacy, commitment, and positive work ethics that can limit exclusion. Our study noted that passionate teachers are loving, caring, and ambitious (Allen \& Cowdery, 2015; McLeskey et al., 2017), so they are more likely not only to accept all children, but also to collaborate with other stakeholders, including parents, to promote inclusive practice. As Ackah-Jnr (2018, p. 14) argues, teachers who are motivated have favorable qualities and they can "stretch out and reach out to more children in early childhood settings" and schools. Teachers with effective qualities would thus support and provide the leadership for enhancing inclusive practice.

The final insight unveiled is that effective training and PD are important and improve IE. Training and PD is a key system and school-level resource which underpins successful IECE (Ackah-Jnr, 2018; Deiner, 2013). If effectively provided, training can be a springboard for "creating positive attitudes and allaying apprehensions and concerns of teachers" implementing IE (Smith et al., 2012, p. 42). Sharma (2018) considers that to develop effective teachers for IE, teacher education programs must prepare them holistically to develop three key elements or apprenticeships-apprenticeship of the head: cognitive knowledge and theoretical basis of the profession; apprenticeship of the heart: the ethical and moral dimensions of a profession, attitudes, and beliefs that are critical to one's professions; and apprenticeship of the hand: the technical and practical skills required to carry out the tasks relevant to one's profession. As the findings show, when teachers learn, they complement the formal PD they receive. This shows that through agency, teachers can enhance their knowledge, skills, and competence. Thus, teachers can engage purposefully in actions to augment their professionalism or motivation for IE practice.

While results offer insights into the prospects of IE, there is a need to explore some areas in-depth. It is suggested a large-scale study be conducted into contextual factors that explain teacher resistance or exclusion of children with disability, even those supposedly having mild to moderate disability, that Ghana's IE policy endorses. Possibly, a study exploring, if any, the relationship between teacher resistance, attitudes, and motivation for IE is required. Since the study data are from one large ECE setting and school in one 
metropolis that is supported by a partner higher education institution, participants' actual encounters with IE may differ from teachers or headteachers elsewhere. The study could as well be replicated. Results are based on selective views, so they must be interpreted with caution, although they still provide useful insights into inclusive practice.

In conclusion, while the focus of this study is on Ghana, the findings will have broad appeal and be of interest to schools and educators across the globe. The study shows there is an interplay of exclusion practices, teacher qualities, and PD that impacts effective inclusion in ECE. It is clear exclusion is a product of teacher decisions, actions, and resistance, but effective teacher qualities and PD are essential to enabling IE. Possibly inclusions and exclusions co-exist, but what is more important is limiting the degree of exclusion to maximize children's participation, learning, and socialization in early childhood education. Particularly, intentional exclusion should not be countenanced as this enforces gatekeeping, resistive, and restrictive practices. Teachers provide the ground-level leadership for IE to happen, so they need to be supported adequately to demonstrate desirable qualities and acquire key competencies from PD programs to enact appropriate inclusive practices. 


\section{References}

Ackah-Jnr, F. R. (2018). System and school-level resources for transforming and optimising inclusive education in early childhood settings: What Ghana can learn. European Journal of Education Studies, 5(6), 203-220.

Ackah-Jnr, F. R. (2020). “The teacher should be learning”: In-service professional development and learning of teachers implementing inclusive education in early childhood education settings. International Journal of Whole Schooling, 16(2), 93-121.

Ainscow, M. (2020). Promoting inclusion and equity in education: Lessons from international experiences. Nordic Journal of Studies in Educational Policy, 6(1), 7-16. https://doi.org//10.1080/20020317.2020.1729587

Allen, K. E., \& Cowdery, G. E. (2015). The exceptional child: Inclusion in early childhood education (8th ed.). Cengage Learning.

Bartolo, P. A., Bjorck-Akesson, E., Gine, C., \& Kyriazopoulou, M. (2016). Ensuring a strong start for all children: Inclusive early childhood education and care. In A. Watkins \& C. Meijer (Eds.), Implementing inclsuive education: Issues in bridging the policy-practice gap ( pp. 19-35). Emerald Publishing.

Bredekamp, S. (2020). Effective practices in early childhood education: Building a foundation (4th ed.). Pearson.

Cologon, K. (2014). Better together: Inclusive education in the early years. In K. Cologon (Ed.), Inclusive education in the early years (pp. 1-26). Oxford University Press.

Creswell, J. W. (2013). Qualitative inquiry \& research design: Choosing among five approaches (3rd ed.). SAGE.

Creswell, J. W., \& Creswell, J. D. (2018). Research design: Qualitative, quantitative, and mixed methods approaches (5th ed.). SAGE.

Deiner, P. L. (2013). Inclusive early childhood education: Development, resources and practice (6th ed.). Cengage Learning.

Essa, E. (2014). Introduction to early childhood education (7th ed.). Cengage Learning.

Fluckiger, B., Dunn, J., Stinson, M., \& Wheeley, E. (2017). Leading age-appropriate pedagogies in the early years of school. Department of Education and Training, Griffith Institute for Educational Research.

Forlin, C., \& Sin, K.-F. (2017). In-service teacher training for inclusion: Best practice models for professional learning. In G. Noblit (Ed.), Oxford research encyclopedia of education. Oxford University Press.

Ghana Statistical Service. (2010). 2010 Population and Housing Census. Ghana Statistical Service.

Government of Ghana. (1992). The Constitution of the Republic of Ghana. Ghana Publishing Company.

Graham, L., \& Scott, W. (2016). Teacher preparation for inclusive education: Initial teacher education and in-service professional development.

http://www.deafeducation.vic.edu.au/Documents/NewsEvents/LitRevIncTe.pdf

Guralnick, M. J., \& Bruder, M. B. (2016). Early childhood inclusion in the United States: Goals, current status, and future directions. Infants \& Young Children, 29(3), 166-177.

Hyde, M. (2014). Understanding diversity, inclusion and engagement. In M. Hyde, L. Carpenter, \& R. Conway (Eds.), Diversity, inclusion \& engagement (pp. 3-38). Oxford University Press.

Kuyini, A. A. R., \& Abosi, O. C. (2014). Teacher effectiveness in adapting instruction to the needs of pupils with learning difficulties in regular primary schools in Ghana. SAGE Open, 4, 1-16. https://doi.org/10.1177/2158244013518929

McLeskey, J. L., Rosenberg, M. S., \& Westling, D. L. (2017). Inclusion: Effective practices for all students: Pearson. 
Miles, M. B., Huberman, A. M., \& Saldana, J. (2014). Qualitative data analysis: A methods sourcebook (3rd ed.). SAGE.

Miles, S., Westbrook, J., \& Croft, A. (2018). Inclusions and exclusions in rural Tanzanian primary schools: Material barriers, teacher agency and disability equality. Social Inclusion, 6(1), 73-81.

Ministry of Education. (2015). Inclusive education policy. Government of Ghana.

Ministry of Education. (2012). Education strategic plan (ESP) 2010 to 2020: Policies, strategies, delivery, finance. Government of Ghana.

Ministry of Education. (2017). National teachers'standards for Ghana: Guidelines. Government of Ghana.

OECD. (2015). Skills for social progress: The power of social and emotional skills. https://www.keepeek.com/Digital-Asset-Management/oecd/education/skills-for-socialprogress_9789264226159-en\#page1

Opoku, M. P., Rayner, C. S., Pedersen, S. J., \& Cuskelly, M. (2019). Mapping the evidence-based research on Ghana's inclusive education to policy and practices: A scoping review. International Journal of Inclusive Education, 1-17. https://doi.org/10.1080/13603116.2019.1600055

Patton, M. Q. (2015). Qualitative research \& evaluation methods: Integrating theory and practice (4th ed.). SAGE.

Sharma, U. (2018). Preparing to teach in inclusive classrooms. In G. Noblit (Ed), Oxford Research Encyclopedia of education (pp. 1-22). Oxford University Press.

Smith, T. E. C., Polloway, E. A., Patton, J. R., \& Dowdy, C. A. (2012). Teaching students with special needs in inclusive settings (6th ed.). Pearson Education Inc.

Tomlinson, C. A. (2014). The differentiated classroom: Responding to the needs of all learners (2nd ed.). ASCD.

UNICEF Ghana (n.d). Convention on the rights of the child. https://www.unicef.org/ghana/convention-rights-child

United Nations (2016). The sustainable development goals report 2016. https://www.un.org.lb/Library/Assets/The-Sustainable-Development-Goals-Report-2016-Global.pdf

United Nations (2006). Covention on the Rights of Persons with Disabilities. http://www.un.org/disabilities/documents/convention/convoptprot-e.pdf

UN Committee on the Rights of the Child (2006). General comment No. 7 (2005): Implementing child rights in early childhood. https://sites.unicef.org/earlychildhood/files/Guide_to_GC7.pdf

Udah, H. (2021). Coloniality of power and international students experience: What are the ethical responsibilities of social work and human service educators? Ethics and Social Welfare.

Wolf, S. J. (2020). “Me I don't really discuss anything with them”: Parent and teacher perceptions of early childhood education and parent-teacher relationships in Ghana. International Journal of Educational Research, 99. https://doi.org/10.1016/j.ijer.2019.101525

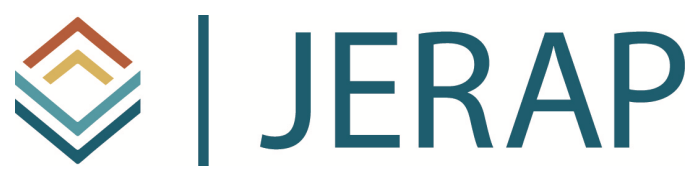

The Journal of Educational Research and Practice is a peerreviewed journal that provides a forum for studies and dialogue about developments and change in the field of education and learning. The journal includes research and related content that

examine current relevant educational issues and processes. The aim is to provide readers with knowledge and with strategies to use that knowledge in educational or learning environments. JERAP focuses on education at all levels and in any setting, and includes peer-reviewed research reports, commentaries, book reviews, interviews of prominent individuals, and reports about educational practice. The journal is sponsored by The Richard W. Riley College of Education and Leadership at Walden University, and publication in JERAP is always free to authors and readers. 